\section{Strengthening the heartbeat}

Traditionally, digitalis has been used to strengthen the force of the heartbeat (its inotropic effect). More recently, however, this action has been said not to be sustained with prolonged treatment. Indeed, the value of digitalis in chronic heart failure may be less than that of potent loop diuretics, which reduce ventricular filling pressure, ${ }^{1}$ while patient compliance with digitalis is low. ${ }^{2}$

In parallel with these criticisms has been a growth of interest in alternative approaches to managing heart failure. Vasodilators may be of value by reducing both ventricular filling pressure (preload) and peripheral resistance (afterload) ${ }^{3}$ -though at present in Britain no vasodilators have a product licence for heart failure. The newer inotropic drugs are mostly analogues of the endogenous catecholamine noradrenaline. None is active by mouth, so they cannot challenge the place of digitalis in long-term treatment: their value is in treating acute heart failure. Depending on their structure, these drugs either release noradrenaline from storage granules within the heart or stimulate cardiac beta-adrenoceptors directly. Treatment with noradrenaline itself is of little value, because in addition to stimulating cardiac beta-adrenoceptors its action on alpha-adrenoceptors in peripheral vessels raises the blood pressure substantially. This is counter-productive for tissue perfusion, and effectively negates any beneficial effects from an increased cardiac output. Isoprenaline has been widely used in intensive care units to increase cardiac output, but its value is limited by its propensity to increase the heart rate excessively and to produce arrhythmias and by its unpredictable effect on blood pressure. Salbutamol has also been used to stimulate cardiac output, but it suffers from many of the same drawbacks as isoprenaline.

The two current front runners among the sympathomimetics are dopamine and dobutamine. Each has its advocates, for they differ both pharmacologically and in their therapeutic profiles. Dopamine is a precursor of noradrenaline, but its inotropic effect is independent of that. ${ }^{4}$ It stimulates cardiac beta-adrenoceptors directly but may have some minor effect in releasing noradrenaline from storage sites in the heart. Its inotropic action is more appreciable than its effect on the heart rate at low doses ( 5 to $10 \mu \mathrm{g} / \mathrm{kg} / \mathrm{min}$ ), and its propensity to cause cardiac arrhythmias is less than that of isoprenaline. In large doses $(30 \mu \mathrm{g} / \mathrm{kg} / \mathrm{min}$ and above) dopamine may act as an alpha-adrenergic stimulant and so raise the blood pressure to an unwanted degree. Dopamine has the valuable action of stimulating vasodilator receptors in the splanchnic and renal bed. ${ }^{5}$ Renal blood flow is increased in normal volunteers ${ }^{6}$ and in patients with heart ${ }^{7}$ or renal ${ }^{8}$ failure, and this, too, may be most beneficial.

Dobutamine, a relative newcomer, is a product of the molecular manipulation of isoprenaline. ${ }^{9}$ Like dopamine, it stimulates cardiac beta-adrenoceptors directly and has a more prominent inotropic than chronotropic effect. Dobutamine does not stimulate peripheral alpha-adrenoceptors to the same extent as dopamine, and unwanted increases in blood pressure are less common. On the other hand, dobutamine does not have the favourable effect of dopamine on renal blood flow. In doses ranging from 2.5 to $15.0 \mu \mathrm{g} / \mathrm{kg} / \mathrm{min}$ dobutamine produces progressive increases in cardiac output in patients with heart failure. ${ }^{10}$

Both dopamine and dobutamine may produce cardiac arrhythmias, albeit considerably less often than isoprenaline, and both must be given by infusion. Much interest has been shown in a new inotropic drug dissimilar in structure to the catecholamines and potentially active by mouth. Amrinone is a bipyridine derivative whose precise mode of action is uncertain. ${ }^{11}$ Its effect is not blocked by beta-adrenoceptor blocking agents or compounds which deplete cardiac catecholamines, so that amrinone does not appear to act through the adrenergic nervous system. A more direct effect on the contractile mechanism of cardiac muscle seems probable. However, unlike digitalis, amrinone does not affect either cyclic AMP or Na-K-ATP'ase activity. The only published studies on its use in patients have been over a few hours. In eight patients in congestive failure, already on therapeutic doses of digitalis, amrinone produced an obvious increase in cardiac output and a fall in ventricular filling pressure and pulmonary capillary wedge pressure without change in systemic pressure or heart rate. In these short-term studies no obvious toxicity was observed. ${ }^{11}$

Many important questions must be answered, however, before we can make any assessment about the usefulness of amrinone long term. How effective is it by mouth? Does tachyphylaxis occur? Does it affect myocardial oxygen consumption adversely? These aspects of the drug will be studied closely in the months to come.

${ }^{1}$ McHaffie, D, et al, Quarterly fournal of Medicine, 1978, 47, 401.

${ }^{2}$ Liverpool Therapeutics Group, British Medical fournal, 1978, 2, 673.

${ }^{3}$ Symposium on Vasodilator and Inotropic Therapy of Heart Failure, American fournal of Medicine, 1978, 65, 101.

${ }^{4}$ McDonald, R H, and Goldberg, L I, fournal of Pharmacology and Experimental Therapeutics, 1963, 140, 60.

${ }^{5}$ Goldberg, L I, Pharmacological Reviews, 1972, 24, 1.

${ }^{6}$ McDonald, R H, et al, fournal of Clinical Investigation, 1964, 43, 1116.

7 Goldberg, L I, American fournal of Cardiology, 1968, 22, 177.

${ }^{8}$ Orme, M, Breckenridge, A M, and Dollery, C T, European fournal of Clinical Pharmacology, 1973, 6, 150.

${ }^{9}$ Sonnenblick, E H, Frishman, W H, and le Jemtel, T H, New England Journal of Medicine, 1979, 300, 17.

${ }^{10}$ Leier, C B, Webel, J, and Bush, C A, Circulation, 1977, 56, 468.

${ }^{11}$ Benotti, J R, et al, New England fournal of Medicine, 1978, 299, 1373.

\section{Centenary of Sir Arthur Hurst}

Centenaries - and some are more boring than others-provide nostalgia for those who knew the individual concerned and an excuse for dinners and meetings for anyone else. They are more desirable in the arts, where, for example, music may be enjoyed, than in science, where progress is the mode and churning up the past may be dull for those not historically minded.

Arthur Hurst, however, was never dull either as a man or as a writer. Born on 23 July 1879, he was a physician at Guy's when the consultant staff were the gods of medicine and surgery, often unchallengeable by the most senior registrar, didactic in teaching, and usually uninterested in research. He showed that medicine was dynamic and not static, and fired those around him with new ideas. He was a rebel in an age when ex-cathedra statements were the rule. His writings ${ }^{1}$ make good reading. He worked in neurology and psychiatry, especially during the first world war, but then gastroenterology became his dominant interest. He debunked many of the current ideas: for example, flatulence (showing that it was due to aerophagy and not fermentation of food); adhesions (that these are symptomless except when causing mechanical obstruction); visceroptosis (then a fashionable alibi for 
abdominal neurosis and lucrative for surgeons who fixed the dropped organs in their supposedly correct position). Other essays, reminiscent of Asher's Talking Sense, were "Mythical Maladies" and "Sins and Sorrows of the Colon"-a protest against the popular belief in purgatives and intestinal lavage. This approach, together with some physiological studies on the sensibility of the alimentary tract and his classic work on its motility by the bismuth meal $x$-ray examination, put gastroenterology on the map as a scientific subject. Later important contributions concerned achalasia, hiatus hernia, psychological aspects of dyspepsia, and megacolon.

Hurst died in 1944, and the story of his life ${ }^{2}$ is the story of medicine in the first part of the 20th century, and will no doubt be discussed at the special centenary meeting organised by Dr Thomas Hunt to be held at the Royal College of Physicians of London on 23 July. Hurst had an international outlook and, at a time when medical travel was less common than today, visited many clinics abroad. His success in private practice was subordinated to hospital work, though this was then the consultant's sole income. He founded a gastroenterological club in 1935-the birth of the British Society of Gastroenterology. Neither asthma nor deafness deterred him; indeed, if attacked by breathlessness during a teaching round, he would inject himself with adrenaline in the ward sister's office and carry on. His conspicuous hearing apparatus was used intently in any lecture which he found interesting, but would be switched off if he found the speaker trite or uninspiring. He was always ready to accept changing concepts. When asked for reprints of his papers, he once wrote that they always seemed to be out of date. ${ }^{3}$

True or false is a formula that can be fairly applied to the works of anyone who has made original contributions; and, of course, Hurst was wrong in some things. So is everyone who produces new ideas. The way to avoid this is to go through a medical career immune to progress, averse to original thought, and hidebound with obsolete ideas learnt as a student.

1 Thomas Hunt, ed, Selected Writings of Sir Arthur Hurst. London, British Medical Association for the British Society of Gastroenterology, 1970.

${ }^{2}$ Hurst, A F, Essays and Addresses on Digestive and Nervous Diseases and on Addison's Anaemia and Asthma. London, Heinemann, 1924.

${ }^{3}$ A Twentieth Century Physician: Being the Reminiscences of Sir Arthur Hurst. London, Arnold, 1949.

\section{Non-specific genital infection}

The unsatisfactory diagnosis of non-specific genital infection is usually made when efficient routine microbiological techniques fail to identify any of the common genital pathogens in appropriate specimens. Clinically, most such cases present as non-gonococcal urethritis in men, but non-specific cervical and vaginal infections are also extremely common.

Among the 229806 men attending venereal disease clinics as new patients in Britain in 1976 a non-specific genital infection was diagnosed in $32 \%$; nearly all had non-gonococcal urethritis. Non-specific genital infection is now by far the most common of the sexually transmitted diseases, and, furthermore, its frequency has increased more rapidly than any other in the past 25 years. Willcox ${ }^{1}$ has pointed out that many further cases of non-gonococcal urethritis are concealed under the diagnosis of gonorrhoea. After treatment of gonorrhoea with penicillin about half the men will be found to have non-specific infection. While many of these will have symptoms and so receive treatment, their female partners are likely to be given treatment only for gonorrhoea.

The common presentation of non-gonococcal urethritis is with discharge, mild dysuria, and frequency. The discharge is usually slight and greyish, though on occasions it is profuse and frankly purulent. Sometimes the urethral secretion is so slight as to go unremarked by both patient and doctor, when the accompanying symptoms of dysuria and frequency may lead to extensive investigation. In such cases a few observant (and often introspective) patients may notice a urethral discharge-but only before the first micturition of the day. When there is a clinically significant infection a first specimen of urine will always show characteristic threads or a faint haze of pus, while subsequent specimens will be clear. Such findings always indicate a need for urethral smears and cultures to exclude subacute gonorrhoea.

Asymptomatic non-gonococcal urethritis is common: Rodin $^{2}$ found it in $12 \%$ of asymptomatic men attending a venereal disease clinic. Most patients with frank urethritis are referred to clinics because of the probability of gonorrhoea, but men with subacute symptoms are often treated by family doctors. ${ }^{3}$ Among the reasons why non-specific genital infection and especially non-gonococcal urethritis are unsatisfactory diagnoses is the gap between theory and practice in their diagnosis. At least half of the episodes of non-gonococcal urethritis are due to infection with Chlamydia trachomatis; but, since appropriate cultural and serological tests are not generally available, precise diagnosis is rarely possible in an individual case.

Empirical antibiotic trials have shown good results in non-specific genital infections only with the tetracyclines and the macrolide antibiotics. ${ }^{4}$ In vitro $C$ trachomatis is sensitive to these drugs, ${ }^{5}$ and clinical trials have confirmed that they are effective in treating urethritis associated with this agent, the clinical response coinciding with the disappearance of the organism from the urethra. The same drugs seem equally effective in cases of chlamydia-negative urethritis. Oriel et al ${ }^{6}$ did note, however, that in a few cases the agent persisted in spite of a 14-day course of treatment (and reinfection seems an unlikely explanation), so that the cure rate is not $100 \%$.

How then should non-specific genital infection be managed -at least in its most familiar clinical presentation as nongonococcal urethritis ? Treatment with oxytetracycline, $250 \mathrm{mg}$ six hourly, or a triple tetracycline, $300 \mathrm{mg}$ twice daily, should be continued for 14 days. Ideally consumption of milk products should cease during treatment, since they reduce absorption of these drugs, though not of doxycycline. Another alternative is erythromycin stearate. Side effects with these regimens are generally few. Female consorts should be examined and treated for any specific infections; in addition, consorts should always have a similar course of tetracyclines or erythromycin. During pregnancy or lactation only erythromycin should be used; in pregnancy some clinicians may prefer to postpone treatment until after delivery. The newborn child should then have close supervision. Sexual intercourse should be firmly banned while either partner is undergoing treatment and the reason explained-namely, the risk of reinfection. Banning alcohol is more controversial: even if the advice is actually taken the benefit is not clear. ${ }^{\text {? }}$

If symptoms persist, a further 10 days' treatment with the chosen antibiotic will often achieve a cure. If the female partner or partners have not been examined, the possibility of an underlying trichomonas infection should be considered. Even when attempts to identify trichomonads by urethral 